\title{
Colitis Cystca Profunda causing colo-colic intussusceptions in an adult
}

\author{
Singh MP' 1 , Paramhans $\mathrm{D}^{2}$, Patel $\mathrm{U}^{3}$, Agarwal V \\ ${ }^{1}$ Dr. Mahendra Pratap Singh, MBBS, MS, Assistant Professor, LN Medical College, Bhopal, India, ${ }^{2}$ Dr. D. Paramhans, MBBS, \\ MS, Professor, LN Medical College, Bhopal, India, ${ }^{3}$ Dr. Umesh Patel, MBBS, MD, Assistant Professor, LN Medical College, \\ Bhopal, India, Dr. Vandana Agarwal, MBBS, MD, Assistant Professor, LN Medical College, Bhopal, India.
}

Address for Correspondence: Dr. M.P Singh, Email: dr_mp_singh@yahoo.com.in

\begin{abstract}
A 62 years old male with colo-colic intussusception caused by colitis cystica profunda is reported. Patient was admitted with features of complete intestinal obstruction. Patient had the history of altered bowel habits and per rectal discharge of altered blood and mucous for six months. Contrast enhanced CT abdomen showed a transverse colonic mass with colocolic intussusception. With provisional diagnosis of carcinoma colon as a causative lesion, left radical hemi-colectomy was performed. Intussuscepted segment had colitis cystic profunda histopathologically. The diagnosis of this entity is important as it can mimic mucin-secreting adenocarcinoma and therefore may result in radical surgical resection.
\end{abstract}

Keywords: Colitis cystica profunda, Colo-colic intussusceptions, Colonic carcinoma.

\section{Introduction}

Colitis cystica profunda is a rare benign condition characterised by mucin filled cyst located in sub mucosa in colon and rectum producing polypoid masses. Contrary to name most lesions have been described as occurring in the rectum. Rarely it does involve more than on segment of the bowel [1]. It is commonly associated with solitary rectal ulcer (SRUS) and rectal mucosal prolapsed syndromes [2]. Colonic Intussusceptions is uncommon in adult and presentation with complete obstruction is rare.

\section{Case report}

A 62 years old male patient presented in emergency room with severe colicky pain in left upper quadrant of abdomen and constipation for two days. Medical history revealed that his symptoms began six months back with mild to moderate colicky abdominal pain associated with altered bowel habits and passing of black coloured stool mixed with copious amount of mucus and occasional fresh blood. He did not have fever, vomiting, anorexia or weight loss. He was an alcoholic and a chronic smoker. There was no history of previous surgery or trauma. There was no family history of colonic polyposis or inflammatory bowel disease.

On examination, abdomen was distended, tense with mild tenderness over left upper quadrant but no peritoneal sign. Bowel sound was slightly increased. Digital rectal examination revealed no mass. Blood investigations at time of admission showed mild leucocytosis with predominant polymorphs and elevated ESR but all other laboratory findings including CEA level were within normal limits.

Plain erect radiograph of abdomen showed distended transverse and ascending colon with non visualized descending colon. Tranabdominal ultra sonography showed target lesion in left hypochondrium suggestive of colonic intussusception. Contrast enhanced computed tomography (CECT) abdomen showed intussusception of left transverse colon with a mass lesion (Fig.1) Colonoscopy could not be done as the patient was in obstruction. With above history and findings, a provisional diagnosis of malignancy of the colon leading to intussusception was made. On abdominal exploration, the omentum, peritoneal surfaces and liver were normal. 


\section{Case Report}

Dilated small and large bowel loops upto transverse colon distally were traced. A large $8 \mathrm{~cm} \mathrm{x} 8 \mathrm{~cm}$, firm, edematous, rubbery colocolic intussuscepted mass was palpated at the splenic flexure. Distal descending colon and sigmoid colon were collapsed. There was no evidence of vascular compromise. Remaining part of intestine was grossly normal. Left radical hemi-colectomy was performed.
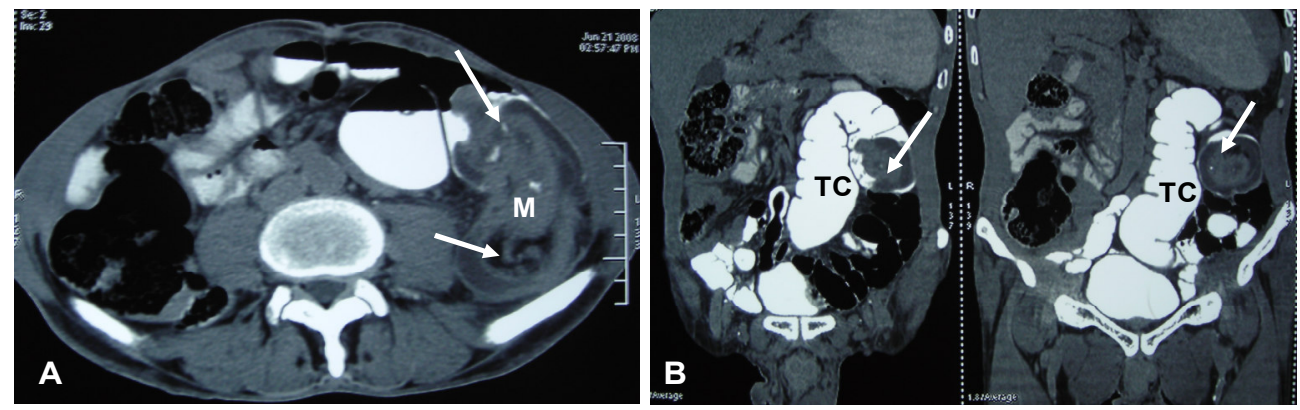

Figure1: CECT axial section (A) showing telescoping of segment of transverse colon (long white arrow) inside the splenic flexure. A suspicious mass $(M)$ is seen in the lead point along with mesenteric fat (short white arrow). Coronal Section (B) showing the mass (long white arrow) and proximally dilated transverse colon (TC)

Gross examination of specimen shows an intraluminal polypoidal structure. The sub mucosal space was expanded by mucinous material, which can be appreciated on both mucosal cut surfaces of specimen.

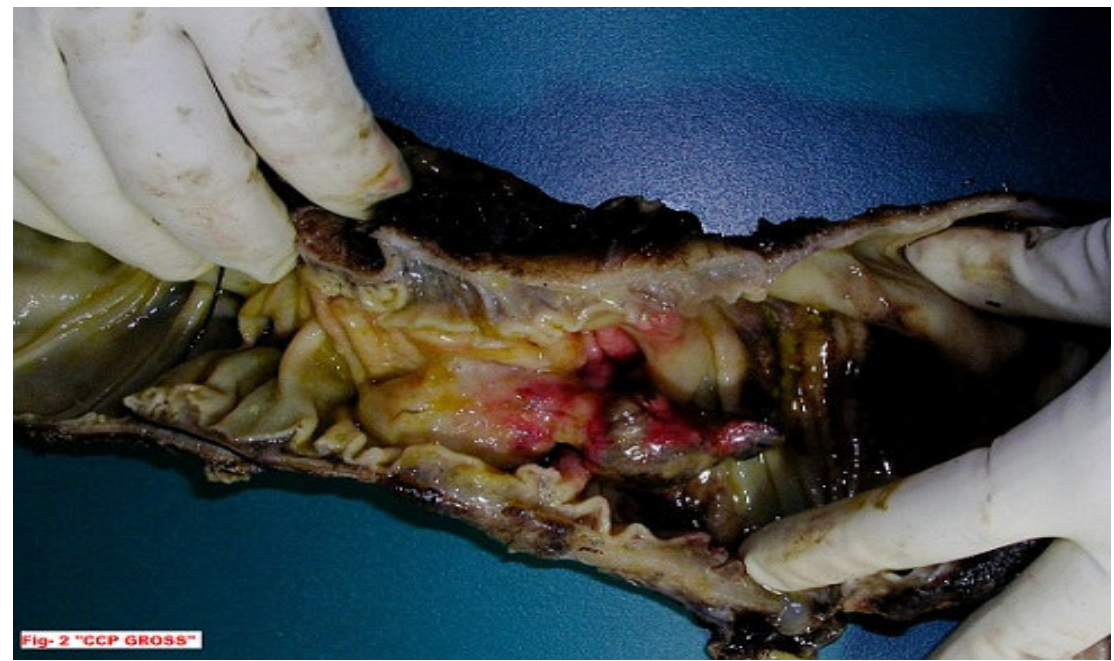

Fig 2: Gross examination of specimen shows an intraluminal polypoidal structure.

On histopathological microscopic examination there were submucosal clusters of benign glandular structures showing mucinous columnar lining with extracellular large pool of mucin, reaching close to muscularis propria. Desmoplastic reaction is not evident around these sub mucosal glands.(Fig 3). There was no evidence of malignancy. Lymphnodes examination showed reactive changes. 


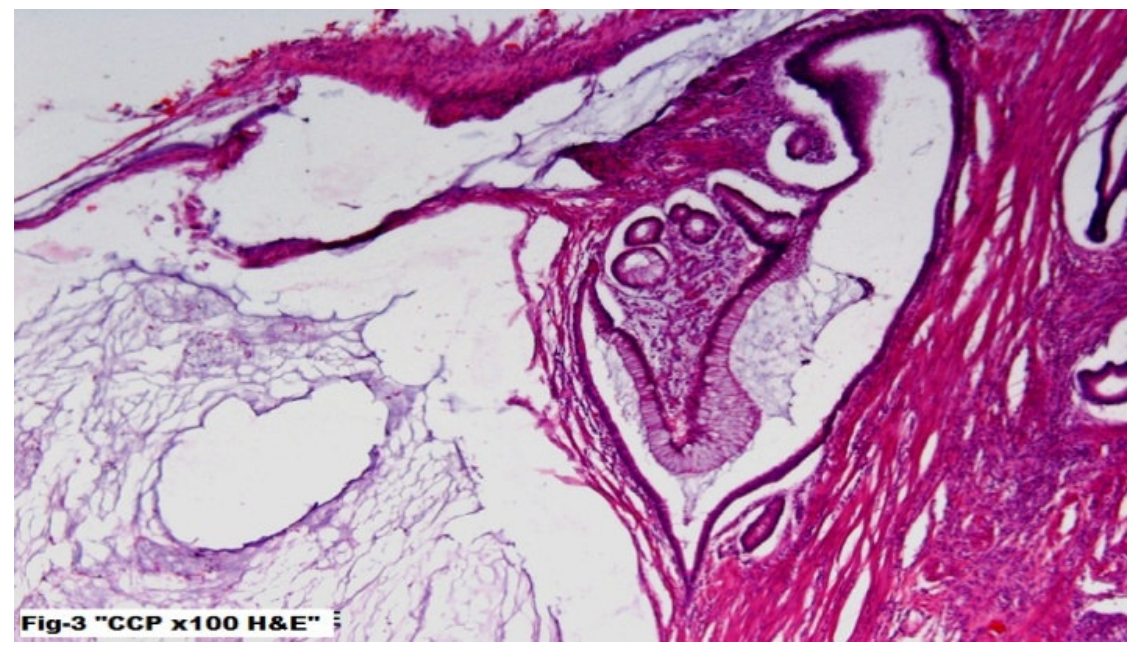

Case Report

Fig 3: histopathological microscopicexamination

\section{Discussion}

Colitis cystica profunda is an exceedingly rare benign condition characterized by mucin filled cyst located in submucosa in colon and rectum producing polypoid masses. CCP is most commonly seen in the third and forth decades of life, but may occur at any age. They can be progressive and diffuse or localized and frequently recur after surgical ablation of affected zone [3].

Etiology and pathogenesis of CCP is uncertain. Support for a congenital pathogenesis is based on embryological study, pediatric case reports, and the association of the related disorders with genetic disease. The acquired pathogenesis theory is supported by the absence of CCP in pediatric autopsy series, the association of the disorder with the conditions involving irritation of the bowel wall $[4,5]$. Regression of the lesion after diverting colostomy, and experimental studies implicating an inflammatory aetiology. The preponderance of evidences favours an acquired aetiology.

The most frequent presenting symptoms are per rectal discharge of blood, mucous, diarrhoea, tenesmus, abdominal pain/cramps/discomfort and rectal pain that may occur alone or in combination for many months before they are diagnosed [6]. Findings on physical examination vary with distribution of the disease. Local form is often discovered on digital palpation of rectum. Typically lesions occur within $10 \mathrm{~cm}$ of anal verge, however they have been reported as for proximal as ascending colon. Large lesions may produce partial intestinal obstruction or even complete obstruction [7] CCP is often mistaken for mucinous carcinoma and invasive carcinoma. Ilio-ileal intussusceptions in child caused by enteritis cystica profunda have been reported [8]. Intussusception is uncommon in adults. Approximately 5\% of the bowel obstructions in adult are results of intussusceptions. In more than $90 \%$ of cases an identifiable lesion resulting in lead point is demonstrable with neoplasm accounting for $50-65 \%$.

Consequently, non operative reduction is not a treatment of choice as in case of child. Most recent reports recommend selective approach to resection, keeping in mind that the site of intussusception tends to correlate with lesion being benign or malignant [9]. Imaging modality including Ultra sono graphy, CT and MRI can be used to accurately diagnose CCP preoperatively $[10,12]$. In our case both transabdominal ultra sonography and contrast enhanced CT abdomen revealed colonic mass with intussusception, but mistakenly diagnosed as malignancy. Colonoscopy with biopsy, which is confirmatory was not done here as patient presented with complete obstruction. CCP may also represent premalignant change or the initial pathological feature of malignancy but nuclear morphology of the epithelium in CCP is not neoplastic $[11,12]$.

\section{Conclusion}

Colitis cystica profunda is an exceedingly rare benign disorder of uncertain etiology, characterized by mucin-filled cyst located in submucosa in colon and rectum producing 


\section{Case Report}

polypoidal mass that may lead to colonic intussusception in adult and may present as complete obstruction. Diagnosis requires high degree of suspicion clinically and radiologically and typical histological finding on adequate biopsy and can be treated by simple excision. The diagnosis of this entity is important as it can mimic mucin-secreting adenocarcinoma and therefore may result in unnecessary surgical resection.

\section{References}

1. Wayte D.M.,and Helwig E. B. Colitis Cystic Profunda. Am. J. Clin. Pathol.1967; 48:159-60.

2. Park HJ, Kim WH, Woo JS, et al. Solitary rectal ulcer syndrome. Yonsei Med J.1994; 35(2):223-30.

3. Magidson JC, Lewin KJ. Diffuse colitis cystic profunda: report of a case. Am J Surg Pathol 1981; 5(4):393-99.

4. Alexis J, Lubin J,Wallack M. Enteritis cystica profunda in a patient with Crohns disease. Arch Path Lab Med.1989; 113(8):947-9.

5. Dippolito AD, Aburano A, Bezouska CA, Happ RA. Enteritis cystica profunda in Peutz-Jeghers syndrome. Report of a case and review of literature. Dis Colon rectum. 1987; 30(3):192-8.

6. Guest CB, Reznick RK. Colitis cystica profunda: Review of the literature.Dis Colon Rectum. 1989; 32(11):983-8.
7. Bentley E, Chandrasoma P, Cohen H, Radin R, Ray M. Colitis cystica profunda: presenting with complete intestinal obstruction and recurrence. Gastroenterology 1985; 89(5):1157-61.

8. Sunagawa H, Kinjyou T, Nagahama M, Nishimaki T, Nakayama T. Enteritis cystic profunda presenting as ilioileal intussusception in a child: report of a case. Surg Today 2005; 35(2):164-67.

9. Zubaidi A, Al-Saif F, Silverman R. Adult intussusceptions: a retrospective review.Dis Colon Rectum.2006; 49(10):154651.

10. Velenzuela M, Martin-Ruiz JL, Alvarez-Cienfueg E, Cabollero AM, Gallego F, Carmonal I, Rodriguez-Tellez M. Colitis cystic profunda: imaging diagnosis and conservative treatment: report of two cases. Dis Colon Rectum. 1996; 39(5):587-590.

11. Sakurai Y, Kobayashi H, Imazu H,Hasegawa S, Mastubara T,Ochiai M, Funabiki T, Mizoguchi Y. The development of an elevated lesion associated with colitis cystic profunda in the transverse colonic mucosa during the ulcerative colitis: report of a case. Surg Today 2000; 30(1):69-73.

12. Wayte DM, Helwing EB. Colitis Cystica Profunda. Am J Roentgenol.1978;131:529-30.

\section{How to cite this article?}

Singh MP, Paramhans D, Patel U, Agarwal V. Colitis Cystca Profunda causing colo-colic intussusceptions in an adult. Int J Med Res Rev 2013;1(1):27-30. doi: 10.17511/ijmrr.2013.i01.05. 